\title{
ANTI-OPTIMIZATION PROBLEMS ARISING IN OPTIMIZATION OF STRUCTURAL STEELWORK
}

\author{
Mahfouz, S. Y. " and Toropov, V.V. **
}

\begin{abstract}
In this paper a structural optimization technique based on a genetic algorithm (GA) is presented. The technique is developed to deal with discrete structural optimization of 2D steel frame structures. Also, from a structural point of view, the paper explores the maximum ratio of the effective buckling length when using the finite element approach and that by the British Standard (BS 5950) approach.

In order to consider realistic steelwork design problems, the developed technique has been linked to a system of structural design rules (British Standards BS 5950 and BS 6399), interacting with a finite element package (ANSYS). In the formulation of the optimization problem, the objective function is the maximum ratio of the effective buckling length of a column evaluated by FEM and that by BS5950. The crosssectional properties of the structural members, which form the set of design variables, are chosen from two separate catalogues (universal beams and columns covered by British Standards BS 4). The constraints are imposed on the design
criteria stipulated by BS 5950 .

Two 2D steel frame structures having different number of design variables and subjected to multiple loading cases are analyzed. These examples show that the developed technique based on GA can be successfully incorporated in discrete structural optimization problems of steel frame structures.
\end{abstract}

\section{KEYWORDS}

Structural optimisation, Genetic algorithm, Buckling length, Steel frame.

*Egyptian Armed forces,

* Professor of computational mechanics, Department of Civil and Environmental Engineering, University of Bradford, Bradford, BD 7 1DP, UK 


\section{NOMENCLATURE}

\begin{tabular}{|c|c|}
\hline$F_{i}(x)$ & Objective function \\
\hline$N_{\mathrm{p}}$ & Population size \\
\hline$E_{\mathrm{r}}$ & Elite ratio \\
\hline$P_{\mathrm{c}}$ & Probability of crossover \\
\hline$P_{\mathrm{m}}$ & Probability of mutation \\
\hline$P_{i}^{\text {sel }}$ & Probability of selection \\
\hline$G_{r, n^{\text {mem }}}^{\text {Str, } q}(x)$ & The $r^{\text {th }}$ Strength constraint of the member $n^{\text {mem }}$ at the $q$ loading case \\
\hline$G_{s, n^{\text {mem }}}^{\text {Sle }}(x)$ & The $s^{\text {th }}$ slenderness constraint of the member $n^{\text {mem }}$ \\
\hline$G_{t, n^{\mathrm{mem}}}^{\mathrm{Ser}}(\boldsymbol{x})$ & The $t^{\text {th }}$ serviceability constraint of the member $n^{\text {mem }}$ \\
\hline
\end{tabular}

\section{INTRODUCTION}

The stability limit state is very important criterion in the design of steel structures Therefore, many authors, among them Lokkas [1], Essa [2] and Mahfouz [3] drew attention to the need for the use of more accurately evaluated critical buckling load (e.g. by the finite element method). Hence, the effective buckling length of each member of the structure can be evaluated after computing the internal force of each member at the critical buckling load (see, Toropov et. al. [4])

The main task of a structural designer is to achieve a safe and economical design The safe design can be determined using the design rules (e.g. codes of practice). Because of the large number of redundancy of the indeterminate structures, the economical design can be achieved when using an optimizer.

For steelwork, the practical optimization problem has features. These features are discussed by many authors among them Huang and Arora [5] and Camp et.al. [6]. The most important one out of these is the nature of the design variables, i.e. the relationship between the cross sectional properties of standard sections. This feature can be clarified by investigating the properties of these sections. Here, Figures 1 and 2 are depicted for the properties of the universal beams (UBs) and universal columns (UCs) from British Standard (BS 4) [7]. The cross-sectional areas and second moment of areas about the major $\mathrm{X}$ axis are depicted in Figures $1 \mathrm{a}$ and $2 \mathrm{a}$ for UBs and UCs respectively. For the same sections, the second moment of area about the major $\mathrm{X}$ and minor $\mathrm{Y}$-axes are displayed in Figures $1 \mathrm{~b}$ and $2 \mathrm{~b}$ for UBs and UCs respectively. The cross sections are drawn in descending order with respect to their second moment of areas about $\mathrm{X}$-axis. The properties of these sections are taken from Steel Construction Institute [8].

From these figures, it can be concluded that there is no one-to-one relationship between area and second moment of area for the group of sections, UBs or UCs. This makes it difficult to find an accurate relationship between the design variables and objective or constraint functions. Therefore, it is necessary to develop an optimization tool that does not need any relationship between the constraint or objective function and the design variables.

In order to optimize structural steelwork, various optimization algorithms have been linked to the structural analysis software since early 1960 s with varied degree of 
success. A study of this experience allows to formulate the following four main requirements to an optimization procedure. Firstly, the technique should be able to handle real life structural design problems. Secondly, the technique has to require a minimum amount of auxiliary information to guide the search. Thirdly, the technique shall attempt to reach the global optimum. Lastly, the technique should be able to handle discrete variables (e.g. selection of properties from a catalogue). A Genetic Algorithm (GA) has been chosen in the present study as the basis for the development of an efficient steelwork optimization algorithm because it satisfies the aforementioned essential requirements, and also for its robustness and its ability to obtain more than one good solution. Various aspects of genetic algorithms are discussed in details by many authors among them Davis [9], Goldberg [10] and Michalewicz [11].

A typical GA is a relatively slow technique (as compared to the derivative-based ones), so an attempt was made to introduce some modifications to the basic procedure in order to improve its rate of convergence. Recently, several attempts have been made, among them Mahfouz [3], Adachi and Yoshida [12] and Arakawa and Hagiwara [13] to improve the performance of a GA by modifying the crossover and mutation operators.

A typical steelwork structural optimization problem can be formulated to include limitations on stresses, displacements, frequencies of vibration, prevention of buckling and other additional requirements to the structural behavior stipulated by the appropriate code of practice for structural steelwork. Here, the British code of practice BS 5950 is used. Out of a number of papers published in the recent years on the subject of structural steelwork optimization, only a few deal with constraints commonly used in steelwork design practice, among them Grierson and Lee [14], Balling [15] and Saka [16].

In this work, The developed optimization technique based on GA is presented and linked to a system of structural rules, interacting with FE package, ANSYS [17], in order to obtain the maximum discrepancy of the effective buckling length of a column evaluated by FEM and that using the BS 5950 approach [18].

\section{GENETIC ALGORITHM (GA)}

\section{Basic idea of a standard GA}

The basic mechanics of a GA is based on the randomized procedures of copying binary strings representing individual strings and swapping partial strings. A basic genetic algorithm consists of three main operators, namely, reproduction, crossover and mutation. In the reproduction process, the individual strings are copied according to their fitness (value of the objective function including a penalty for the possible violation of constraints). The reproduction operator can be implemented in a number of ways, the most popular being simulation of a biased roulette wheel with slots of different width representing the proportion of the fitness of an individual string. The crossover operator normally proceeds in two steps: firstly, two strings (parents) in the newly reproduced population are randomly selected and, secondly, each pair of parents undergo swapping parts of their strings at randomly selected positions thus producing two new strings (children). Lastly, in order to introduce new strings, the mutation stage takes place with a low probability. This stage prevents the search from premature convergence to a non-optimal solution and improves non-local 


\section{The developed elite strategy}

When using the traditional simple GA, it has been observed that the best individual of the population may fail to produce offspring for the next generation. The elitist strategy, developed by Davis [9], fixes this potential source of loss by copying the best individual of each generation into succeeding generation. Consequently, the elitist strategy increases the speed of domination of a population by an individual. It appears to improve genetic algorithm performance (see, Mahfouz et. al. [19], [20]). The elitist strategy developed keeps the best individuals with a certain percentage termed elite ratio $E_{\mathrm{r}}$ of the population. This strategy can be described as follows:

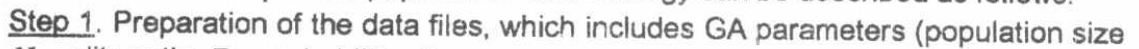
$N_{\mathrm{p}}$, elite ratio $E_{\mathrm{r}}$, probability of crossover $P_{\mathrm{c}}$, probability of mutation $P_{\mathrm{m}}$, crossover operator required and seed number).

Step 2. Creation of population with number of individuals equals to $N_{\mathrm{p}}$.

Step 3. Calculation of the objective function $F_{i}\left(i=1,2, \ldots N_{\mathrm{p}}\right)$ for each individual.

Step 4. Check of the feasibility of each individual using the predefined constraints.

Step 5. Computation of the value of the penalized objective function $P F_{i}$.

Step 6. Searching of the smallest $P F_{\text {best }}$ and largest $P F_{\text {worst }}$ value of the penalized objective function out of whole population $N_{\mathrm{p}}$

Step 7. Evaluation of the fitness function $\left(F F_{i}\right)$ for all individuals:

$$
F F_{i}=P F_{\text {best }}+P F_{\text {werst }}-P F_{i} .
$$

Step 8. Sorting the whole population $N_{\mathrm{p}}$ according to the value of fitness function $\left(F F_{i}\right)$ of each individual where the largest value of $F F_{i}$ is the best.

$\underline{\text { Step } 9}$. Calculation of the average fitness value $\left(F F_{\text {av }}\right)$ using:

$$
F F_{\mathrm{av}}=\frac{\sum_{i=1}^{N_{\mathrm{p}}} F F_{i}}{N_{\mathrm{p}}} .
$$

Step 10. Killing all individuals whose fitness value below the average fitness $F F_{\text {av }}$. Step 11. In the surviving part $N_{\text {sur }}$, finding of the new value of the largest penalized objective function $P F_{\text {worst }}^{\text {new }}$ which is slightly above $F F_{\text {av }}$.

Step 12. Defining a new fitness function $F F_{i}^{\text {new }}$ for only the surviving part $N_{s}$ of the population. The fitness function $F F_{i}^{\text {new }}$ is

$$
F F_{i}^{\text {new }}=P F_{\text {best }}+P F_{\text {worst }}^{\text {new }}-P F_{i} \text {. }
$$

Step 13. Calculation of the probability of selection $P_{i}^{\text {sel }}$ of all the surviving individuals using 


$$
P_{i}^{\text {sol }}=\frac{F F_{i}^{\text {new }}}{\sum_{j=1}^{N_{s}} F F_{j}^{\text {new }}} .
$$

Step 14. Filling in the new population. Here, the new population consists of: - part 1 contains the elite individuals. The number of these individuals $N_{\mathrm{c}}$

$$
N_{\mathrm{e}}=E_{\mathrm{r}} N_{\mathrm{p}}
$$

and it is filled by copying the best individuals out of the current population, - part 2 contains the number of individuals $\left(N_{\mathrm{c}}\right)$ after crossover, where

$$
N_{\mathrm{c}}=P_{\mathrm{c}} N_{\mathrm{p}}
$$

and it is filled by selecting its individuals according to the probability of selection discussed in step 12 and crossover the parents.

- The rest of population (part 3) whose number of individuals $\left(N_{\mathrm{r}}\right)$ is computed from

$$
N_{\mathrm{r}}=\left\{\begin{array}{ll}
N_{\mathrm{p}}-\left(N_{\mathrm{c}}+N_{\mathrm{c}}\right) & \text { if } P_{\mathrm{c}}+E_{\mathrm{r}}<1 \\
0 & \text { if } P_{\mathrm{c}}+E_{\mathrm{r}}=1
\end{array} .\right.
$$

and it is filled by randomly selecting its individuals from surviving part $N_{\text {sur }}$.

Step 15. Check of the termination condition. In the present study, three termination conditions are used and if any of them is satisfied, then the process will terminate. These conditions are

- If the fittest design has not changed for 30 successive generations, or if the difference between the fittest $F^{\mathrm{cu}}$ of the current generation and that of 30 generations before is very small value $C^{\mathrm{cu}}$. This could be expressed in the form

$$
\frac{F^{\mathrm{cu}}-F^{\mathrm{cu}-30}}{F^{\mathrm{cu}}} \leq C^{\mathrm{cu}}
$$

- As we proceed with more generation the population gets filled by more fit individuals, with perhaps a very small deviation from the fitness of the best individuals. Consequently, the average fitness comes very close to the fitness of the best design. This could result in another convergence criterion such that the percentage difference between the average fitness $F^{\mathrm{av}}$ of the current population and the current fitness of the best design $F^{\mathrm{cu}}$ reaches a very small value $C^{\mathrm{av}}$. This can
be expressed by

$$
\frac{F^{\mathrm{cu}}-F^{\mathrm{av}}}{F^{\mathrm{cu}}} \leq C^{\mathrm{av}}
$$


- When a total allocated number of generations $\left(\right.$ gen $^{\max }=200$ ) are reached If the conversion is satisfactory, then stop the program. If not, continue. Step 16. Performing the mutation. The number of binary digits $N U_{\mathrm{d}}$ that are changed can be computed from

$$
N U_{\mathrm{d}}=N_{\mathrm{p}} P_{\mathrm{m}} \ell_{n_{\mathrm{v}}}^{\mathrm{T}}
$$

where $\ell_{n_{\mathrm{v}}}^{\mathrm{T}}$ is the number of chromosomes (string length) of one individual, and $P_{\mathrm{m}}$ is the probability of mutation.

Step 17. The process is repeated from step 3 to step 15 until a converged solution is obtained, or a prescribed maximum number of iterations have been performed.

\section{FORMULATION OF THE OPTIMIZATION PROBLEM}

Assume the framework in the global coordinate system $\left(X^{\prime}-Y^{\prime}-Z^{\prime}\right)$ displayed in Figure 3 where $\Delta_{Y^{\prime}, n_{\mathrm{c}}^{\text {mem }}}^{\mathrm{U}}$ and $\Delta_{\mathrm{Y}^{\prime}, n_{\mathrm{c}}^{\text {mem }}}^{\mathrm{L}}$ are the horizontal displaceinents of the upper and lower nodes of a column $n_{\mathrm{c}}^{\mathrm{mem}}$ and $\delta_{n_{\mathrm{b}}^{\operatorname{mem}}}^{\max }$ is the maximum vertical displacement within a beam $n_{\mathrm{b}}^{\mathrm{mem}}$. In this figure, $N_{\mathrm{c}}^{\mathrm{mem}}$ and $N_{\mathrm{b}}^{\mathrm{mem}}$ describe the total number of column and beam members respectively. The total number of members is $N^{\text {mem }}$. The number of stories and bays are defined by $N_{\mathrm{s}}$ and $N_{\mathrm{b}}$ respectively. The height of the $n_{\mathrm{s}}{ }^{\text {th }}$ storey is $h_{n}$. The general formulation of the optimization problem can be expressed by

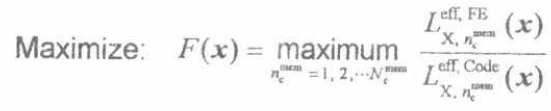

$$
\begin{aligned}
& \text { Subject to: } \quad G_{r, n^{\mathrm{mem}}}^{\text {Str, } q}(x) \leq 1, r=1,2,3,4, q=1,2, \cdots, Q \\
& G_{s, n^{\text {mem }}}^{\text {Sle }}(x) \leq 1, s=1,2 \\
& G_{t, n^{\text {Inem }}}^{\text {Ser }}(x) \leq 1, t=1,2,3 \\
& \frac{I_{\mathrm{x}}^{n_{\mathrm{s}}, n_{\mathrm{b}}}}{I_{\mathrm{x}}^{n_{\mathrm{s}}-1, n_{\mathrm{b}}}} \leq 1, n_{\mathrm{s}}=1,2, \cdots, N_{\mathrm{s}}, n_{\mathrm{b}}=1,2, \cdots, N_{\mathrm{b}}+1 \\
& \boldsymbol{x}=\left(x_{1}^{T}, x_{2}^{T}, x_{j}^{T}, \cdots, x_{j}^{T}\right), j=1,2, \cdots, J \\
& x_{i, j} \in D_{j} \text { and } \\
& D_{j}=\left(d_{j, 1}, d_{j, 2}, \cdots, d_{j, \ell}\right)
\end{aligned}
$$

where $I_{\mathrm{x}}^{n_{s} \cdot n_{b}}$ and $I_{\mathrm{x}}^{n_{x}-1, n_{\mathrm{b}}}$ are the second moments of area of the cross sections of two columns in two adjacent storey levels about the major $X$-axis. The vector of design variables $x$ is divided into $J$ sub-vectors $x_{J}$. The components of these sub- 
Proceedings of the $9^{\text {th }}$ ASAT Conference, 8-10 May 2001 Paper ST-20 581 vectors take values from a corresponding catalogue $D_{j}$. In the present work, the cross-sectional properties of the structural members, which form the design variables, are chosen from two separate catalogues (universal beams and columns covered by BS 4). The normalized constraints $G_{r, n^{\operatorname{mem}}}^{\mathrm{Str}, q}(x), G_{s, n^{\operatorname{mem}}}^{\mathrm{Sle}}(x)$ and $G_{t, n^{\mathrm{mem}}}^{\mathrm{Ser}}(x)$ represent the strength, slenderness and serviceability criteria stipulated by BS 5950 respectively and these can be evaluated using the following procedure. Step 1. Preparation of data files and these include framework geometry, loading

Step 2. Classification of the framework into sway or non-sway. This is achieved by applying the notional horizontal loading case. A framework, analyzed without including the effect of cladding, is classified as non-sway if the difference between the upper $\Delta_{Y^{\prime}, n_{\mathrm{c}}^{\mathrm{mem}}}^{\mathrm{U}}(\boldsymbol{x})$ and lower $\Delta_{Y^{\prime}, n_{\mathrm{c}}^{\mathrm{mem}}}^{\mathrm{L}}(\boldsymbol{x})$ horizontal nodal displacements of each column member $n_{\mathrm{c}}^{\text {mem }}$ satisfies the following condition:

$$
\frac{\left|\Delta_{Y^{\prime}, n_{\mathrm{c}}^{\text {mem }}}^{\mathrm{Um}}(\boldsymbol{x})-\Delta_{Y^{\prime}, n_{\mathrm{c}}^{\text {mem }}}^{\mathrm{L}}(\boldsymbol{x})\right|}{\left(\frac{L_{n_{\mathrm{c}}^{\text {mem }}}}{2000}\right)} \leq 1, n_{\mathrm{c}}^{\text {mem }}=1,2, \cdots, N_{\mathrm{c}}^{\text {mem }} .
$$

where $x$ is the vector of design variables, $L_{r_{\mathrm{c}}^{\text {mem }}}$ is the length of the column under consideration. The indices $U$ and $L$ indicate the position of the upper and lower ends
of a column.

Step 3. Calculation of the effective buckling lengths $L_{\mathrm{X}, n^{\text {mem }}}^{\text {eff }}$ and $L_{\mathrm{Y}, n^{\text {mem }}}^{\text {eff }}$ of columns and beams. For columns, $L_{\mathrm{X} \cdot n_{\mathrm{c}}^{\text {mem }}}^{\text {eff }}$ is determined according to one of the following approaches:

- using the charts from BS 5950

- a more accurate method mentioned by $\mathrm{SCl}$ [21], based on finite element alysis, see Toropov et al. [4];

The effective buckling length $L_{\mathrm{X}, n_{\mathrm{b}}^{\mathrm{mem}}}^{\mathrm{eff}}$ of a beam equals the unrestrained length of the compression flange that occurs on the underside of a beam, see MacGiniey [22]. To evaluate $L_{\mathrm{Y}, n^{\mathrm{mem}}}^{\mathrm{eff}}\left(x_{i, j}\right)$ of beams and columns, It is presupposed that the lateral bracing system restrain members from movements out of plane $\left(X^{\prime}-Z^{\prime}\right.$ plane $)$ at their mid spans. Thus, $L_{\mathrm{Y}, n^{\mathrm{mem}}}^{\mathrm{eff}}\left(x_{i, j}\right)$ equals to the half of the length of the member $L_{n}$

Step 4. Calculation of the slenderness ratios $\lambda_{\mathrm{X}, n^{\text {mem }}}(x)$ and $\lambda_{\mathrm{Y}, n^{\text {mem }}}\left(x_{i, j}\right)$ of the member $n^{\mathrm{mem}}$ using

$$
\lambda_{\mathrm{X}, n^{\mathrm{ment}}}(x)=\frac{L_{\mathrm{X}, n^{\mathrm{mem}}}^{\mathrm{eff}}(\boldsymbol{x})}{r_{\mathrm{X}, n^{\mathrm{mem}}}}
$$




$$
\lambda_{\mathrm{Y}, n^{\text {mem }}}\left(x_{i, j}\right)=\frac{L_{\mathrm{Y}, n^{\text {mem }}}^{\mathrm{eff}}\left(x_{i, j}\right)}{r_{\mathrm{Y}, n^{\text {mem }}}} .
$$

where $r_{\mathrm{X}, n^{\text {nem }}}$ and $r_{\mathrm{Y}, n^{\mathrm{mem}}}$ are the radius of gyrations of the section about $\mathrm{X}$ and $\mathrm{Y}$ axes respectively and $x_{i, j}$ is a design variable $i$ from the sub-vector $j$.

Step 5. Check of the slenderness constraints $G_{s, n}^{\text {Sle }}$ Sen for each member using

$$
G_{s, n^{\text {mem }}}^{\text {Sie }}(x) \leq 1, s=1,2 .
$$

where

$$
\begin{aligned}
& G_{1, n^{\text {mem }}}^{\text {Sle }}(x)=\frac{\lambda_{\mathrm{X}, n^{\text {mem }}}(x)}{180} \text { and } \\
& G_{2, n^{\text {mem }}}^{\text {Sle }}\left(x_{i, j}\right)=\frac{\lambda_{\mathrm{Y}, n^{\text {mem }}}\left(x_{i, j}\right)}{180} .
\end{aligned}
$$

Step 6. Analysis of the framework under each loading case $q$ to obtain the normal force, shearing forces and bending moment for each member.

Step 7. Check of the strength requirements for each member $n^{\text {mem }}$ under each loading case $q$ and this can be illustrated as follows:

(a) Determination of the type of the section of the member (e.g. slender, semicompact, compact or plastic).

(b) Evaluation of the design strength $p_{y, n \text { men }}$ of the member.

(c) Check of the strength constraints $G_{r, n^{\text {mem }}}^{\text {Str, } q}(x)$ depending on whether the member is in tension or compression where $r$ represents the number of strength constraints. The strength constraints are local capacity, overall capacity, shear capacity and the shear buckling capacity. These constraints should satisfy

$$
G_{r, n^{\operatorname{mem}}}^{\text {Str, } q}(x) \leq 1, r=1,2,3,4 \text { and } q=1,2, \cdots, Q .
$$

where the local capacity

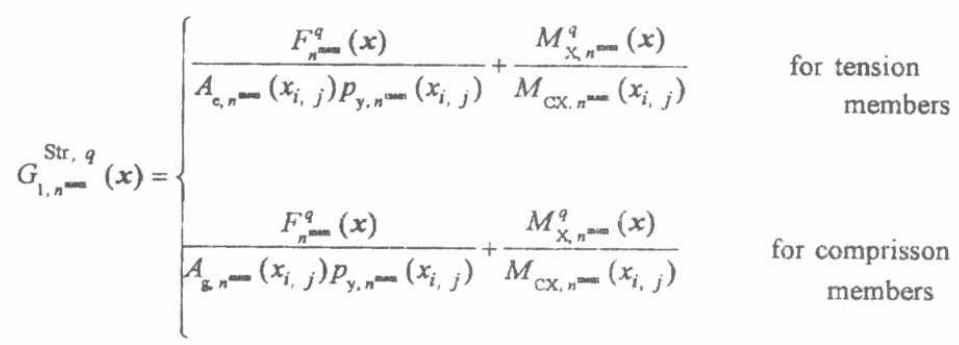

where $F_{n^{\text {mem }}}^{q}(x)$ is the axial force, $M_{\mathrm{X}, n^{\text {mem }}}^{q}(x)$ is the moment about the major local axis $(\mathrm{X})$ at the critical region of the member under consideration, $p_{\mathrm{y}, n^{\mathrm{mem}}}\left(x_{i, j}\right)$ is the 
design strength of the member and $M_{\mathrm{CX}, n^{\mathrm{mem}}}\left(x_{i, j}\right)$ is the moment capacity of the member section about its major local axis $(X)$. The effective area and gross area of the section of the member are $A_{\mathrm{e}, n^{\mathrm{mem}}}\left(x_{i, j}\right)$ and $A_{\mathrm{g}, n^{\mathrm{mem}}}\left(x_{i, j}\right)$.

For each member, the overall capacity $G_{2, n^{\mathrm{mem}}}^{\mathrm{Str}, q}(x)$ is determined by

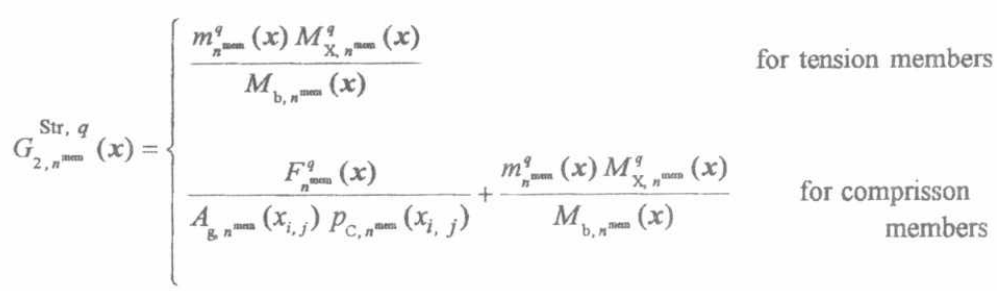

where $m_{\text {mem }}^{q}(x)$ is the equivalent uniform factor for each member under each loading case $q$ and $M_{\mathrm{b}, n \text { mem }}(x)$ is the buckling resistance moment.

The shear capacity $G_{3, n^{\mathrm{mem}}}^{\mathrm{Str}, q}(x)$ is computed by

$$
G_{3, n^{\text {men }}}^{\mathrm{Str}, q}(x)=\frac{F_{\mathrm{Y}, n^{\text {mem }}}^{q}(x)}{P_{\mathrm{Y}, n^{\text {mem }}}\left(x_{i, j}\right)} .
$$

where $P_{\mathrm{Y}, n^{\mathrm{mem}}}\left(x_{i, j}\right)$ is the shear capacity of the member, and $F_{\mathrm{Y}, n^{\mathrm{mem}}}^{q}(x)$ is the maximum value of shear force in the member under the specified loading case $q$. Each member should also satisfy the shear buckling constraint $G_{4, n^{\text {mem }}}^{\text {Str, } q}(x)$ if

$$
\frac{d\left(x_{i, j}\right)}{t\left(x_{i, j}\right)} \geq 63 \varepsilon\left(x_{i, j}\right) .
$$

where $d$ and $t$ are the width and the thickness of the flange plate of the section. Hence, $G_{4, n^{\text {mem }}}^{\text {Str } q}(x)$ is computed by

$$
G_{4, n^{\mathrm{mem}}}^{\mathrm{Str}, q}(x)=\frac{F_{\mathrm{Y}, n^{\mathrm{mem}}}^{q}(x)}{V_{\mathrm{c}, n^{\mathrm{mem}}}\left(x_{i, j}\right)} .
$$

where $V_{\mathrm{cr}, n \text { mem }}\left(x_{i, j}\right)$ is the shear resistance of the member.

(d) For a sway structure, the notional horizontal loading case is considered, this is termed sway stability criterion. 
Step 8. Checks of the horizontal and vertical nodal displacements. These are known as serviceability criteria

$$
G_{t, n^{\text {mem }}}^{\text {Ser }}(x) \leq 1, t=1,2 \text { and } 3 .
$$

This is performed by:

(i) Computing the horizontal nodal displacements due to the unfactored imposed loads and wind loads in order to satisfy the limits on the horizontal displacements,

$$
G_{1, n_{\mathrm{c}}^{\text {mem }}}^{\text {Ser }}=\frac{\left|\Delta_{\mathrm{Y}^{\prime}, n_{\mathrm{c}}^{\text {mem }}}^{\mathrm{U}}(\boldsymbol{x})-\Delta_{\mathrm{Y}^{\prime}, n_{\mathrm{c}}^{\mathrm{Lem}}}^{\mathrm{L}}(\boldsymbol{x})\right|}{\left(\frac{L_{n_{\mathrm{c}}^{\text {mem }}}}{300}\right)} \text { and } n_{\mathrm{c}}^{\text {mem }}=1, \Lambda, N_{\mathrm{c}}^{\text {mem }} \text {. }
$$

where $L_{n_{\mathrm{c}}^{\text {men }}}$ is the length of the column under consideration. The indexes ( $U$ and $L$ ) define the position of the two column ends.

(ii) Imposing the limits on the vertical nodal displacements (maximum value within a beam) due to the unfactored imposed loads.

$$
G_{2, n_{\mathrm{b}}^{\mathrm{mem}}}^{\mathrm{Ser}}(\boldsymbol{x})=\frac{\left|\delta_{n_{\mathrm{b}}^{\text {mem }}}^{\text {max }}(\boldsymbol{x})\right|}{\left(\frac{L_{n_{\mathrm{b}}^{\text {mem }}}}{360}\right)}, n_{\mathrm{b}}^{\text {mem }}=1.2 . \Lambda \cdot N_{\mathrm{b}}^{\mathrm{mem}}
$$

where $L_{n_{\mathrm{b}}^{\text {mem }}}$ is the length of the beam under consideration.

In the present work, it is assumed that $N_{\mathrm{p}}$ is 60 . One point crossover is applied. Probability of crossover $P_{\mathrm{c}}$ and mutation $P_{\mathrm{m}}$ are $70 \%$ and $1 \%$ respectively. The elite ratio $E_{\mathrm{r}}$ is $30 \%$. The simple "exact" penalty function employed is

$$
\text { Minimize } \bar{F}(x)=\left\{\begin{array}{cc}
C-F(x), & \text { all constraints satisfied } \\
0, & \text { any of constraints violated }
\end{array}\right.
$$

The convergence criteria and termination conditions detailed in step 15 of the developed elite strategy are utilised where $C^{\mathrm{av}}=0.001, C^{\mathrm{cu}}=0.001$ and $\operatorname{gen}^{\max }=200$. 


\section{BENCHMARK EXAMPLES}

\section{Example 1: Two-bay Two-storey framework}

The two-bay two-storey framework shown in Figure 4 is considered. In this figure, the framework geometry, the member numbering and the loading pattern for the stability analysis are shown. It is assumed that the spacing between successive frameworks is $8.00 \mathrm{~m}$ where the structure will be used for office block including projection rooms. Seven cases representing the most unfavourable combinations of the factored dead $(D L)$, imposed $(L L)$ and wind $(W L)$ loads are considered. These loading cases can be described as follows:

1. the beams are subjected to the vertical load $P^{v}=1.4 D L+1.6 L L$,

2. the vertical load $P^{v}=1.4 D L+1.6 \mathrm{LL}$ is applied on each floor level while the left hand side of the framework is subjected to the notional horizontal load,

3. the beams of the first bay (counting from the left) are exposed to the vertical load $P^{v}=1.4 D L+1.6 L L$ while the other beams are subjected to $P^{v}=1.4 D L$,

4. the beams of the top right and bottom left stories are subjected to vertical load $P^{v}=1.4 D L+1.6 L L$ while the other beams are subjected to $P^{v}=1.4 D L$,

5. the beams are subjected to vertical load $P^{v}=1.2 D L+1.2 L L$ and the left hand side of the framework is exposed to the factored wind load $P^{h}=1.2 \mathrm{WL}$

6. the beams are subjected to the vertical load $P^{v}=1.0 \mathrm{LL}$ and the left hand side of the framework is exposed to the factored wind load $P^{h}=1.2 \mathrm{WL}$ and

7. the beams are subjected to the vertical load $P^{v}=1.0 \mathrm{LL}$.

The general loading pattern is shown in Figure 5 while the values of the loads $(\mathrm{kN})$ corresponding to these cases are listed in Table 1.

The finite element model was built up in ANSYS using 5 elements for each member of the framework to ensure adequate accuracy when carrying out the stability analysis.

The optimum solution of the problem formulated in the previous section is carried out twice. In the first, the framework members are divided into 4 groups and the section properties of each group form the design variables. The design variable linking is displayed in Figure 6 . The second is similarly considered but 6 design variables are taken into consideration and the linking of design variables are shown in Figures 7. Applying the modified GA, solutions of the problem for the framework having 4 design variables were obtained over five runs. Here, Three out of these runs gave the same value of the maximum ratio $L_{\mathrm{X}, n_{\mathrm{c}}^{\text {mem }}}^{\text {eff } F E} / L_{\mathrm{X}, n_{\mathrm{c}}^{\text {mem }}}^{\text {effi }}$. This value and its corresponding column member of the framework as well as design variables are listed in Table 2. The search history for each run is plotted in Figure 8.

Five runs were also performed for the same framework having 6 design variables representing the framework members. Table 3 describes the best solution obtained. The convergence history for each run is exhibited in Figure 9.

From Figures 8 and 9, it can be observed that the best solution is obtained within 30 generations while the rest of the computation was carried out to satisfy any of the convergence criteria. 


\section{Example 2: Five-bay five-storey framework}

The five-bay five-storey framework, displayed in Figure 10 was analyzed. In this figure, the loading pattern for the stability analysis and numbering of the framewrok members are shown. It is assumed that the spacing between successive frameworks is $5.00 \mathrm{~m}$ and the structure will be used for offices and computer equipment purposes. Eight loading cases representing the most unfavourable combinations of the factored dead load $(D L)$, imposed load $(L . L)$ and wind load $(W L)$ are considered. These loading cases can be described as follows:

1. the beams are subjected to the vertical load $P^{v}=1.4 D L+1.6 L L$

2. the vertical load $P^{v}=1.4 D L+1.6 L L$ is applied on each floor level while the left hand side of the framework is subjected to the notional horizontal load,

3 . the beams of the first two bays (counting from the left) are exposed to the vertical load $P^{v}=1.4 \mathrm{LL}+1.6 \mathrm{LL}$ while the other beams are subjected to $P^{v}=1.4 \mathrm{DL}$,

4. the beams of the first three bays (counting from the left) are subjected to the vertical load $P^{v}=1.4 \mathrm{DL}+1.6 \mathrm{LL}$ while the other beams are subjected to $P^{v}=1.4 \mathrm{DL}$,

5. the vertical loads $P^{v}=1.4 D L+1.6 L \mathrm{~L}$ and $P^{v}=1.4 \mathrm{DL}$. are distributed on staggered way. That means, the loads onto the top-left-storey beams are $P^{v}=1.4 D L+1.6 L L$ while the adjacent beams either in the same storey level or the storey beneath carry
$P^{v}=1.4 D L$.

6. the beams are subjected to vertical load $P^{v}=1.2 D L+1.2 L L$ and the left hand side of the framework is exposed to the factored wind load $P^{h}=1.2 \mathrm{WL}$,

7. the beams are subjected to the vertical load $P^{v}=1.0 \mathrm{LL}$ and the left hand side of the framework is exposed to the factored wind load $P^{h}=1.0 \mathrm{WL}$ and

8. the beams are subjected to the vertical load $P^{v}=1.0 \mathrm{LL}$

The general loading pattern is shown in Figure 11 where the values of the loads corresponding to these cases are listed in Table 4

Again, the optimization problem is sought twice. Firstly, the framework members are divided into 6 groups. The linking between these groups and the member numbering is shown is Figure 12. Secondly, the framework members are divided into 8 groups. The linking of these groups is shown is Figure 13.

The finite element models were built-up in ANSYS using 5 elements for each member. The optimization process was carried out and solutions are obtained.

Table 5 shows the best solution obtained of the optimization problem when 6 design variables are taken into consideration. Figure 14 illustrates the convergence history for each run. Again, using the modified GA, five runs were carried out when having 8 design variables representing the framework members. Table 6 describes the best solution obtained. Figure 15 demonstrates the search history for each run.

From Figures 14 and 15, it can be observed that the best solution is obtained within 50 generations while the rest of the computation was carried out to satisfy any of the
convergence criteria. 


\section{DESCUSSION OF RESULTS AND CONCLUDING REMARKS}

Optimization technique based on GA was applied for structural optimization of steel frame structures. Also in this paper, the difference between the value of the effective length factor of a column determined by the simplified approach presented by BS 5950 and that computed by the finite element approach was investigated.

It can be observed that the effective length factor $L_{\mathrm{X}, n_{\mathrm{e}}^{\operatorname{mex}}}^{\text {eff, } \mathrm{FE}} / L_{n_{\mathrm{e}}^{\operatorname{mem}}}$ computed by the finite element approach is greater than that $L_{\mathrm{X}, n_{\mathrm{c}}^{\operatorname{med}}}^{\text {eff Cod }} / L_{n_{\mathrm{c}}^{\text {mem }}}$ determined by the simplified approach to BS 5950. The difference between these factors depends on the geometric dimensions and section properties of each member of the framework under consideration. The reason behind this difference is obtained because the simplified method adopted by Wood [23] and presented in BS 5950 mainly depends on two assumptions:

a) involving the no-shear stability function only, while the general case of sway is a superposition of no-shear sway and pure--shear sway.

b) the consideration of a limited framework which contains the column under consideration plus all members, in the framework in at either end. This means, the effect of other members not included in the limited framework were neglected.

It can be observed that the position of the column, at which the maximum ratio $L_{\mathrm{X}, n_{\mathrm{c}}^{\mathrm{em}}}^{\mathrm{eff}, \mathrm{FE}} / L_{\mathrm{X}, n_{\mathrm{c}}^{\text {mem }}}^{\text {eff, Code }}$ reached, is located at the top storey level.

It is also shown that size of problem (number of design variables) plays a major role in terms of computational effort needed to reach satisfactory results.

The studied examples demonstrate the potential applications of the modified GA to obtain alternative solutions for complicated problems. Thus, the approach is suitable for the treatment of different problems in the field.

\section{REFERENCES}

[1] Lokkas, P., A consistent approach to the buckling design analysis of rigid jointed steel-frames subject to sidesway, Ph.D thesis, University of London (1996).

[2] Essa, H.S., Stability of columns in unbraced frames. ASCE J. of Structural Engineering Vol. 123, pp.952-95 (1997).

[3] Mahfouz, S. Y., Design opttimization of steelwork structures, Ph.D thesis, University of Bardford, UK, (1999).

[4] Toropov, V.V., Mahfouz, S.Y., Westbrook, R.K., Discrete design optimization of 3dimensional steel structures using a genetic algorithm. Short paper proceedings of the $3^{\text {rd }}$ World Congress of Structural and Multidisciplinary Optimization, Buffalo, NY, USA, May, pp. 269-271, (1999).

[5] Huang, M.W., Arora, J.S., Optimal design of steel structures using standard sections, Structural Optimization, Vol. 14, 24-35 (1997).

[6] Camp, C., Pezeshk, S. and Cao, G., Optimized design of two-dimensional structures using a genetic algorithm, Journal of Structural Engineering, Vol. 124, No.

[7] British Standards Institution, British Standard, Specification for hot-rolled sections BS 4: Part 1, (1993).

[8] The Steel Construction Institute, Steelwork Design Guide to BS 5950: Part 1, Section Properties and Member Capacities, Vol. 1, The Steel Construction Institute,
UK, (1985). 
[9] Davis, L., Handbook of genetic algorithms, Van Nostrand Reinhold, New York, (1991).

[10] Goldberg, D.E., Genetic algorithms in search, optimization and machine learning, Addison-Wesley Publishing Co., Inc., New York, (1989).

[11] Michalewicz, Z., Genetic algorithm + Data structures = Evolution programs, 3rd edition, Springer-Verlag, New York, (1996).

[12] Adachi, N. and Yoshida, Y., Accelerating genetic algorithms: protected chromosomes and parallel processing, 1st IEE/IEEE International Conference on GA in Engineering Systems, pp. 76- 81, (1995).

[13] Arakawa, M. and Hagiwara, I., Development of revised adaptive real range genetic algorithms. Proc. of 2 nd World Congress of Structural and Multidisciplinary Optimization 1, In: Gutkowski, W. and Morz, Z. (ed.), pp. 15-20, Wydawnictwo Ekoinzynieria, Lublin, Poland, (1997).

[14] Grierson, D.E. and Lee, W.H., Optimal synthesis of frame under elastic and plastic performance constraints using discrete sections. J. Struct. Mech., Vol. 14, pp. 401-420, (1986)

[15] Balling, R. J., Optimal steel frames design by simulated annealing, Journal of Structural Engineering, Vol. 117, No. 6, pp. 1780-1795, (1991).

[16] Saka, M. P., Optimum design of grillage systems using genetic algorithrns, Computer-Aided Civil and Infrastructure Engineering, Vol.3, No. 4, pp.297-302, (1998).

[17] ANSYS. 5.3., ANSYS, Inc., Houston, USA, (1996).

[18] British Standards Institution., British Standard. Structural use of steelwork in building. Part 1. Code of practice for design in simple and continuous construction: Hot rolled sections. BS 5950: Part 1, (1990).

[19] Mahfouz, S.Y., Toropov, V.V. and Westbrook, R.K., Improvements in the performance of a genetic algorithm: application to steelwork optimum design, Proceedings of 7th AIAA /USAF/NASAISSMO Symposium on Multidisciplinary Analysis and Optimization, pp. 2037-2045, (1998).

[20] Mahfouz, S.Y., Toropov, V.V. and Westbrook, R.K., Modification, tuning and testing of a GA for structural optimization problems, Proceedings of $1^{\text {st }}$ AMSO UKIISSMO Conference on Engineering Design Optimization, pp. 271-278, (1999).

[21] The Steel Construction Institute., SCI.P.069, Introduction to steelwork design to BS 5950: Part 1, (1988)

[22] MacGinley, T.J., Steel Structures Practical Design Studies. London, E \& FN SPON, (1997).

[23] Wood, R.H., Effective lengths of columns in multi-storey building, Part 1, Structural Engineer, Vol. 52, No. 7, pp. 235-244, (1974). 
Proceedings of the $9^{\text {th }}$ ASAT Conference, 8-10 May 2001

Table 1. Loads applied on the two-bay two-storey framework (in kN)

\begin{tabular}{|c|c|c|c|c|c|c|c|}
\hline \multirow{2}{*}{$\begin{array}{c}\text { Load } \\
\text { symbol }\end{array}$} & \multicolumn{7}{|c|}{ Loading case } \\
\cline { 2 - 8 } & $\mathbf{1}$ & $\mathbf{2}$ & $\mathbf{3}$ & $\mathbf{4}$ & $\mathbf{5}$ & $\mathbf{6}$ & $\mathbf{7}$ \\
\hline$P_{1}$ & 213.2 & 213.2 & 165.2 & 165.2 & 148 & 30 & 30 \\
\hline$P_{2}$ & 346.4 & 346.4 & 218.4 & 346.4 & 283.2 & 80 & 80 \\
\hline$P_{3}$ & 426.4 & 426.4 & 330.4 & 330.4 & 296 & 60 & 60 \\
\hline$P_{4}$ & 692.8 & 692.8 & 436.8 & 692.8 & 566.4 & 160 & 160 \\
\hline$P_{5}$ & 426.4 & 426.4 & 378.4 & 378.4 & 296 & 60 & 60 \\
\hline$P_{6}$ & 692.8 & 692.8 & 564.8 & 564.8 & 566.4 & 160 & 160 \\
\hline$P_{7}$ & 426.4 & 426.4 & 426.4 & 426.4 & 296 & 60 & 60 \\
\hline$P_{8}$ & 692.8 & 692.8 & 692.8 & 436.8 & 566.4 & 160 & 160 \\
\hline$P_{9}$ & 213.2 & 213.2 & 213.2 & 213.2 & 148 & 30 & 30 \\
\hline$P_{10}$ & 346.4 & 346.4 & 346.4 & 218.4 & 283.2 & 80 & 80 \\
\hline$H_{1}$ & 0.0 & 8.5 & 0.0 & 0.0 & 16.7 & 13.9 & 0.0 \\
\hline$H_{2}$ & 0.0 & 13.85 & 0.0 & 0.0 & 29.67 & 24.66 & 0.0 \\
\hline
\end{tabular}

Table 2. Results obtained for maximizing $L_{\mathrm{X}, n_{\mathrm{c}}^{\text {mem }}}^{\mathrm{eff}, \mathrm{FE}} / L_{\mathrm{X}, n_{\mathrm{c}}^{\text {mem }}}^{\text {eff, Code }}$ of columns in the two-bay two-storey framework (4 design variables)

\begin{tabular}{|c|c|c|c|}
\hline Max. $L_{\mathrm{X}, n_{\mathrm{c}}^{\text {mem }}}^{\text {eff } \mathrm{FE}} / L_{\mathrm{X}, n_{\mathrm{c}}^{\mathrm{mem}}}^{\text {eff, Code }}$ & $\begin{array}{c}\text { Member } \\
\text { number }\end{array}$ & \multicolumn{3}{|c|}{ Design variables } \\
\hline \multirow{3}{*}{2.068} & & 1 & $356 \times 406 \times 634 \mathrm{UC}$ \\
\hline \multirow{3}{*}{2} & 2 & $305 \times 305 \times 158 \mathrm{UC}$ \\
\hline & & 3 & $914 \times 419 \times 388 \mathrm{UB}$ \\
\cline { 3 - 4 } & & 4 & $914 \times 419 \times 388 \mathrm{UB}$ \\
\hline
\end{tabular}

Table 3. Results obtained for maximizing $L_{\mathrm{X}, n_{\mathrm{c}}^{\mathrm{mem}}}^{\mathrm{eff}, \mathrm{FE}} / L_{\mathrm{X}, n_{\mathrm{c}}^{\mathrm{mem}}}^{\mathrm{eff}, \text { code }}$ of columns in the twobay two-storey framework (6 design variables)

\begin{tabular}{|c|c|c|c|}
\hline Max. $L_{\mathrm{X}, n_{\mathrm{c}}^{\text {mem }}}^{\text {eff, }} / L_{\mathrm{X}, n_{\mathrm{c}}^{\text {mem }}}^{\text {eff, Code }}$ & $\begin{array}{c}\text { Member } \\
\text { number }\end{array}$ & \multicolumn{3}{|c|}{ Design variables } \\
\hline & & 1 & $356 \times 406 \times 235 \mathrm{UC}$ \\
\hline \multirow{4}{*}{2.135} & & 2 & $203 \times 203 \times 46 \mathrm{UC}$ \\
\hline & 4 & 3 & $356 \times 406 \times 634 \mathrm{UC}$ \\
\hline & & 4 & $356 \times 406 \times 634 \mathrm{UC}$ \\
\hline & & 5 & $914 \times 419 \times 388 \mathrm{UB}$ \\
\hline & & 6 & $914 \times 419 \times 388 \mathrm{UB}$ \\
\hline
\end{tabular}


Proceedings of the $9^{\text {th }}$ ASAT Conference, 8-10 May 2001

Table 4. Loads applied on the five-bay five-storey framework (in $\mathrm{kN}$ ).

\begin{tabular}{|c|c|c|c|c|c|c|c|c|}
\hline $\begin{array}{c}\text { Load } \\
\text { symbol }\end{array}$ & \multicolumn{10}{|c|}{ Loading case } \\
\cline { 2 - 10 } & $\mathbf{1}$ & $\mathbf{2}$ & $\mathbf{3}$ & $\mathbf{4}$ & $\mathbf{5}$ & $\mathbf{6}$ & $\mathbf{7}$ & $\mathbf{8}$ \\
\hline$P_{1}$ & 70 & 70 & 70 & 70 & 70 & 60 & 25 & 25 \\
\hline$P_{2}$ & 140 & 140 & 140 & 140 & 70 & 110 & 60 & 60 \\
\hline$P_{3}$ & 140 & 140 & 140 & 140 & 140 & 110 & 60 & 60 \\
\hline$P_{4}$ & 140 & 140 & 140 & 140 & 140 & 120 & 50 & 50 \\
\hline$P_{5}$ & 280 & 280 & 280 & 280 & 90 & 220 & 120 & 120 \\
\hline$P_{6}$ & 280 & 280 & 280 & 280 & 280 & 220 & 120 & 120 \\
\hline$P_{7}$ & 140 & 140 & 140 & 140 & 105 & 120 & 50 & 50 \\
\hline$P_{8}$ & 280 & 280 & 280 & 280 & 185 & 220 & 120 & 120 \\
\hline$P_{9}$ & 280 & 280 & 280 & 280 & 185 & 220 & 120 & 120 \\
\hline$P_{10}$ & 140 & 140 & 140 & 140 & 70 & 120 & 50 & 50 \\
\hline$P_{11}$ & 280 & 280 & 280 & 280 & 280 & 220 & 120 & 120 \\
\hline$P_{12}$ & 280 & 280 & 280 & 280 & 90 & 220 & 120 & 120 \\
\hline$P_{13}$ & 140 & 140 & 105 & 140 & 105 & 120 & 50 & 50 \\
\hline$P_{14}$ & 280 & 280 & 185 & 280 & 185 & 220 & 120 & 120 \\
\hline$P_{15}$ & 280 & 280 & 185 & 280 & 185 & 220 & 120 & 120 \\
\hline$P_{16}$ & 140 & 140 & 70 & 140 & 140 & 120 & 50 & 50 \\
\hline$P_{17}$ & 280 & 280 & 90 & 280 & 90 & 220 & 120 & 120 \\
\hline$P_{18}$ & 280 & 280 & 90 & 280 & 280 & 220 & 120 & 120 \\
\hline$P_{19}$ & 140 & 140 & 70 & 105 & 105 & 120 & 50 & 50 \\
\hline$P_{20}$ & 280 & 280 & 90 & 185 & 185 & 220 & 120 & 120 \\
\hline$P_{21}$ & 280 & 280 & 90 & 185 & 185 & 220 & 120 & 120 \\
\hline$P_{22}$ & 140 & 140 & 70 & 70 & 60 & 120 & 50 & 50 \\
\hline$P_{23}$ & 280 & 280 & 90 & 90 & 280 & 220 & 120 & 120 \\
\hline$P_{24}$ & 280 & 280 & 90 & 90 & 90 & 220 & 120 & 120 \\
\hline$P_{25}$ & 140 & 140 & 70 & 70 & 105 & 120 & 50 & 50 \\
\hline$P_{26}$ & 280 & 280 & 90 & 90 & 185 & 220 & 120 & 120 \\
\hline$P_{27}$ & 280 & 280 & 90 & 90 & 185 & 220 & 120 & 120 \\
\hline$P_{28}$ & 140 & 140 & 70 & 70 & 140 & 120 & 50 & 50 \\
\hline$P_{29}$ & 280 & 280 & 90 & 90 & 280 & 220 & 120 & 120 \\
\hline$P_{30}$ & 280 & 280 & 90 & 90 & 280 & 220 & 120 & 120 \\
\hline$P_{31}$ & 70 & 70 & 35 & 35 & 70 & 60 & 25 & 25 \\
\hline$P_{32}$ & 140 & 140 & 70 & 70 & 140 & 110 & 60 & 60 \\
\hline$P_{33}$ & 140 & 140 & 70 & 70 & 70 & 110 & 60 & 60 \\
\hline$H_{1}$ & 0.0 & 7 & 0.0 & 0.0 & 0.0 & 6 & 5 & 0.0 \\
\hline$H_{2}$ & 0.0 & 14 & 0.0 & 0.0 & 0.0 & 12 & 10 & 0.0 \\
\hline
\end{tabular}


Table 5. Results obtained for maximizing $L_{\mathrm{x}, \mathrm{FE}}^{\text {eff, }} / L_{\mathrm{X}}^{\text {eff, code }}$ five-bay five-storey framework ( 6 design variables)

\begin{tabular}{|c|c|c|c|}
\hline Max. $L_{\mathrm{X}, n_{\mathrm{c}}^{\text {mem }}}^{\text {eff, FE }} / L_{\mathrm{X}, n_{\mathrm{c}}^{\text {mem }}}^{\text {eff, Code }}$ & $\begin{array}{l}\text { Member } \\
\text { number }\end{array}$ & \multicolumn{3}{|c|}{ Design variables } \\
\hline \multirow{3}{*}{4.1344} & & 1 & $356 \times 406 \times 634 \mathrm{UC}$ \\
\cline { 3 - 4 } & \multirow{3}{*}{10} & 2 & $356 \times 406 \times 634 \mathrm{UC}$ \\
\cline { 3 - 5 } & & 4 & $305 \times 305 \times 118 \mathrm{UC}$ \\
\hline & & 5 & $914 \times 419 \times 388 \mathrm{UB}$ \\
\hline
\end{tabular}

Table 6. Results obtained for maximizing $L_{\mathrm{X}, n_{\mathrm{c}}^{\text {mem }}}^{\text {eff, } \mathrm{FE}} / L_{\mathrm{X}, n_{\mathrm{c}}^{\text {mem }}}^{\text {eff, Code }}$ of columns in the five-bay five-storey framework ( 8 design variables).

\begin{tabular}{|c|c|c|c|}
\hline Max. $L_{\mathrm{X}, n_{\mathrm{c}}^{\mathrm{mem}}}^{\text {eff, FE }} / L_{\mathrm{X}, n_{\mathrm{c}}^{\text {mem }}}^{\text {eff, code }}$ & $\begin{array}{l}\text { Member } \\
\text { number }\end{array}$ & & Design variables \\
\hline \multirow{8}{*}{4.2459} & \multirow{8}{*}{5} & 1 & $356 \times 406 \times 634$ UC \\
\hline & & 2 & $356 \times 406 \times 634$ UC \\
\hline & & 3 & $356 \times 406 \times 634$ UC \\
\hline & & 4 & $254 \times 254 \times 167$ UC \\
\hline & & 5 & $254 \times 254 \times 73$ UC \\
\hline & & 6 & $254 \times 254 \times 73$ UC \\
\hline & & 7 & $914 \times 419 \times 388$ UB \\
\hline & & 8 & $457 \times 191 \times 89$ UB \\
\hline
\end{tabular}




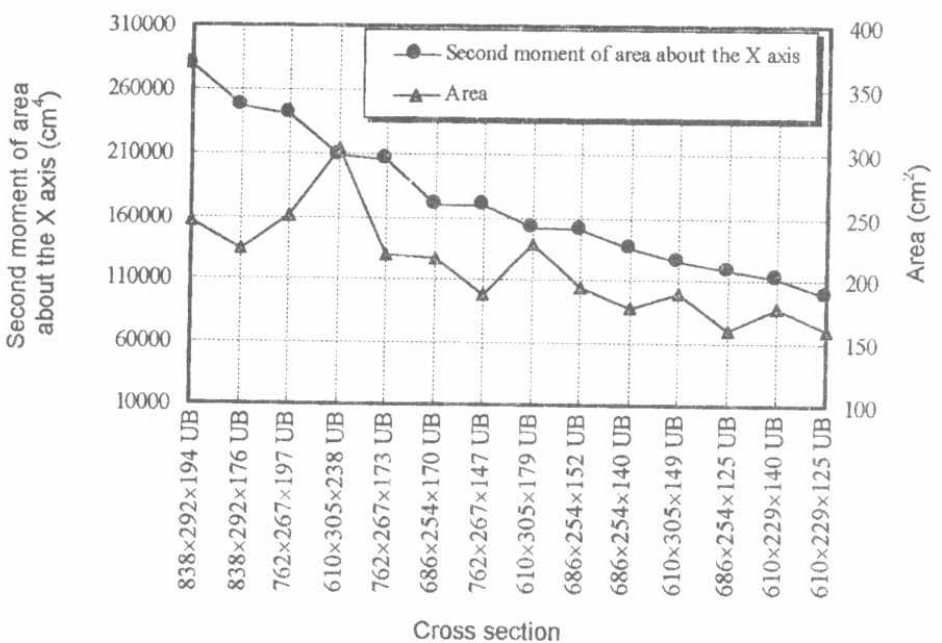

(a) Relationship between the second moment of area about the $X$ axis to area

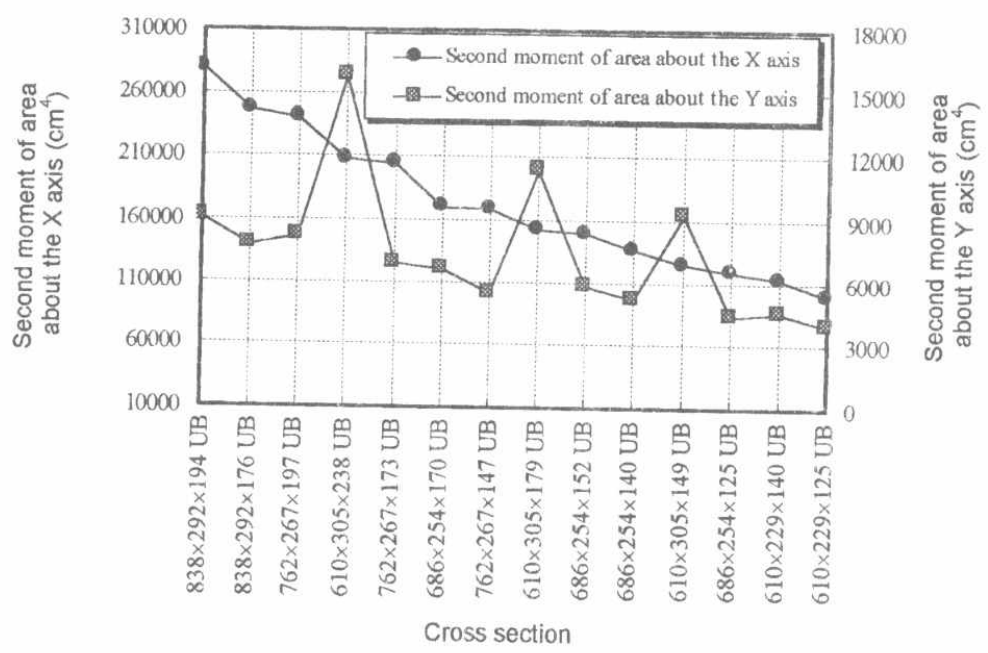

(b) Relationship between the second moment of areas about the $X$ and $Y$ axes

Figure 1. Relationship between the cross sectional properties of universal beams (UBs) 


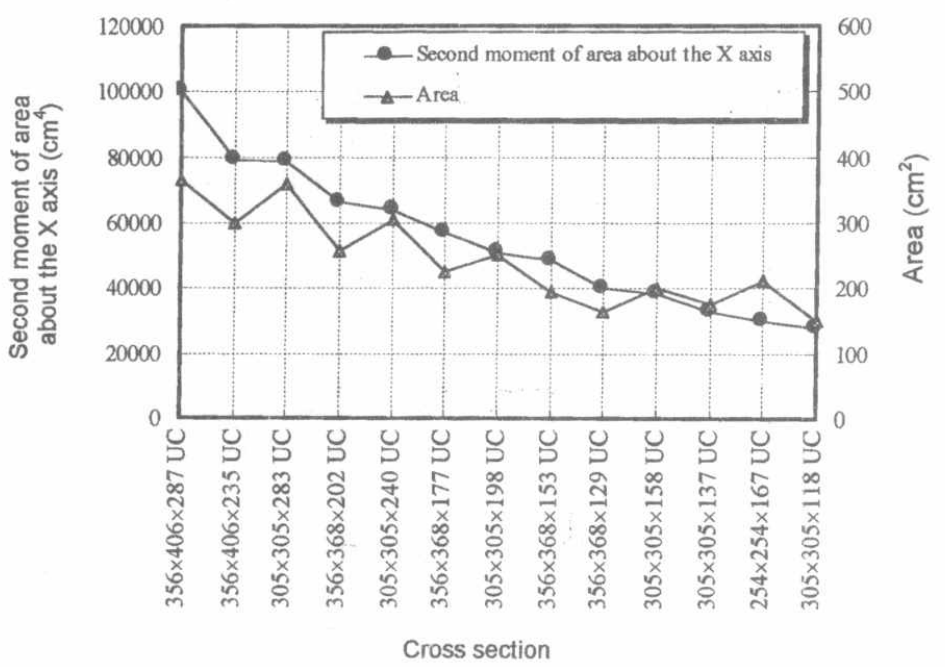

(a) Relationship between the second moment of area about the $X$ axis to area

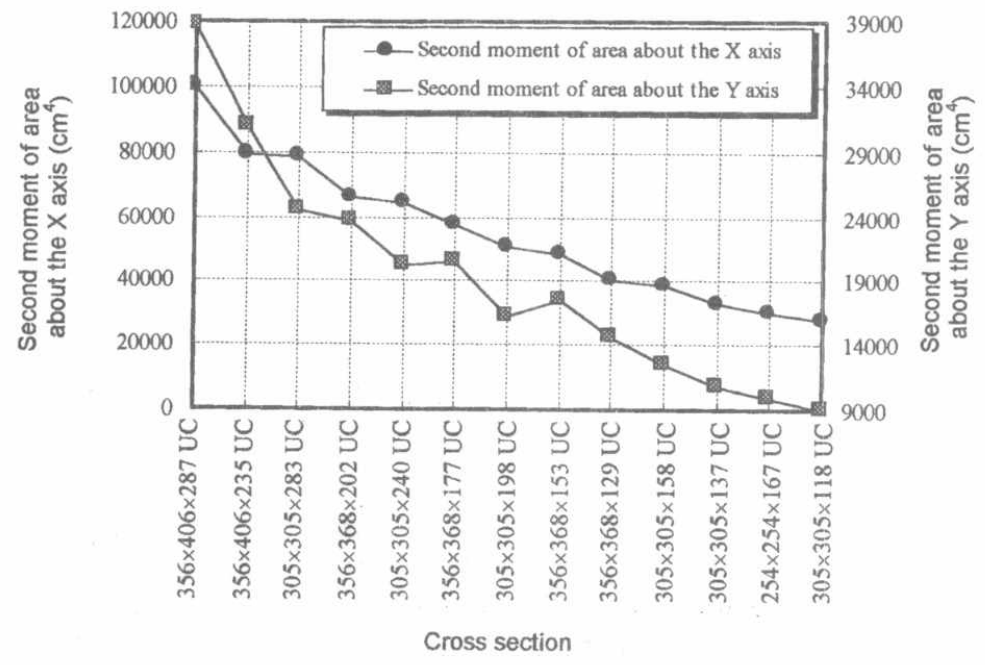

(b) Relationship between the second moment of areas about the $\mathrm{X}$ and $\mathrm{Y}$ axes

Figure 2. Relationship between the cross-sectional properties of universal beams (UCs) 


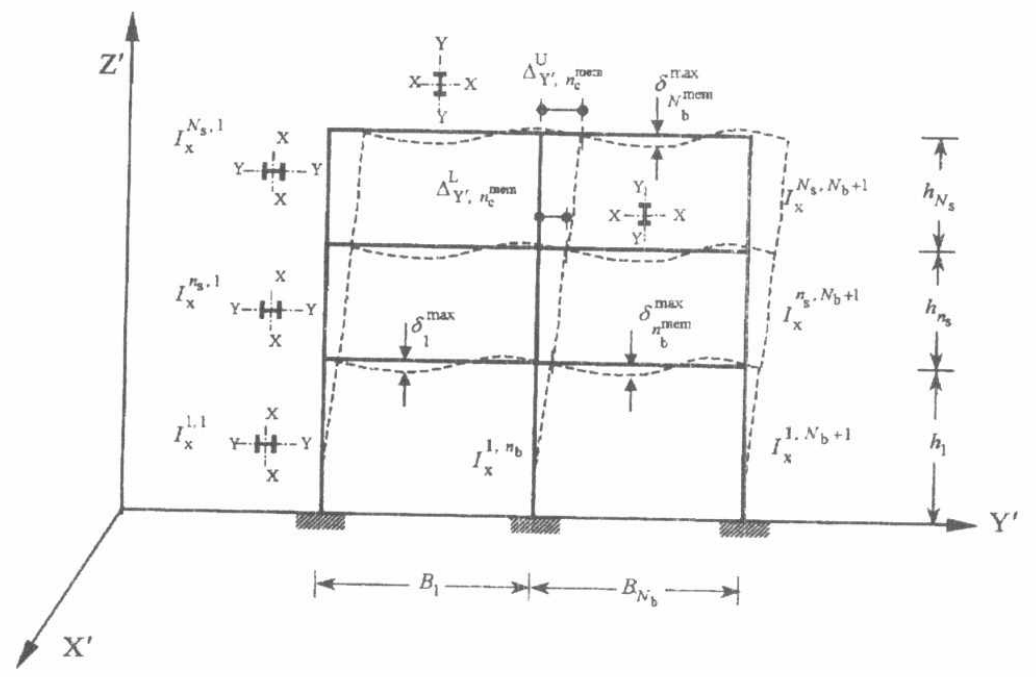

Figure 3. Framework under consideration: coordinate system and notations

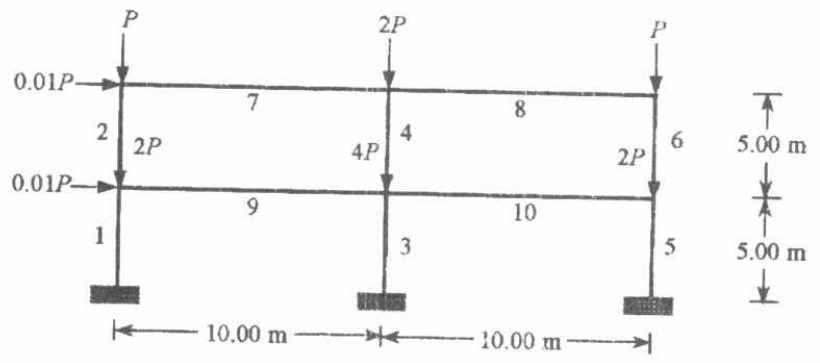

Figure 4. Two--bay two-storey framework: dimensions, member numbering and loading pattern for stability analysis 


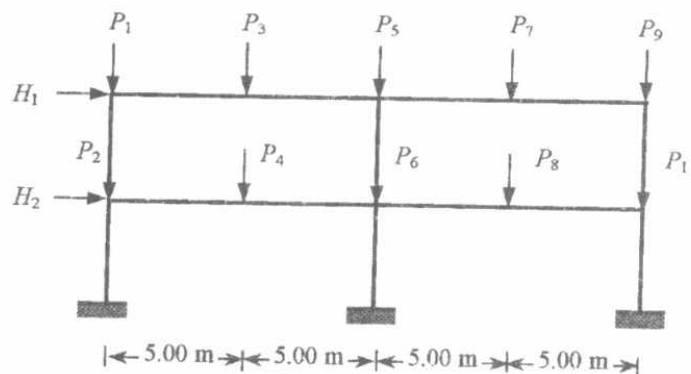

Figure 5. Two-bay two-storey framework: the general loading pattern

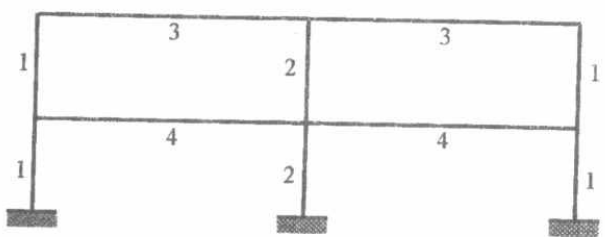

Figure 6. Two-bay two-storey framework: the arrangement of 4 design variables

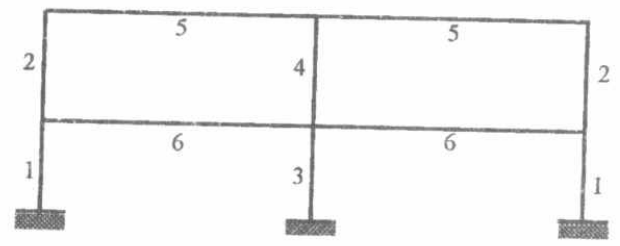

Figure 7. Two-bay two-storey framework: the arrangement of 6 design variables 


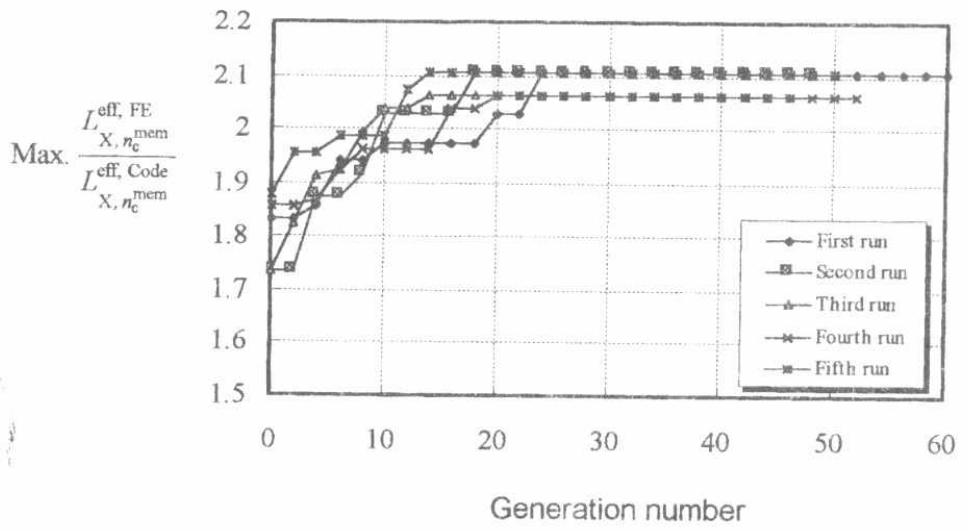

Figure 8. Two-bay two-storey framework (4 design variables): maximum $L_{\mathrm{X}, n_{\mathrm{c}}^{\text {men }}}^{\text {eff } \mathrm{FE}} / L_{\mathrm{X}, n_{\mathrm{c}}^{\text {ment }}}^{\text {eff; Code }}$ versus generation number

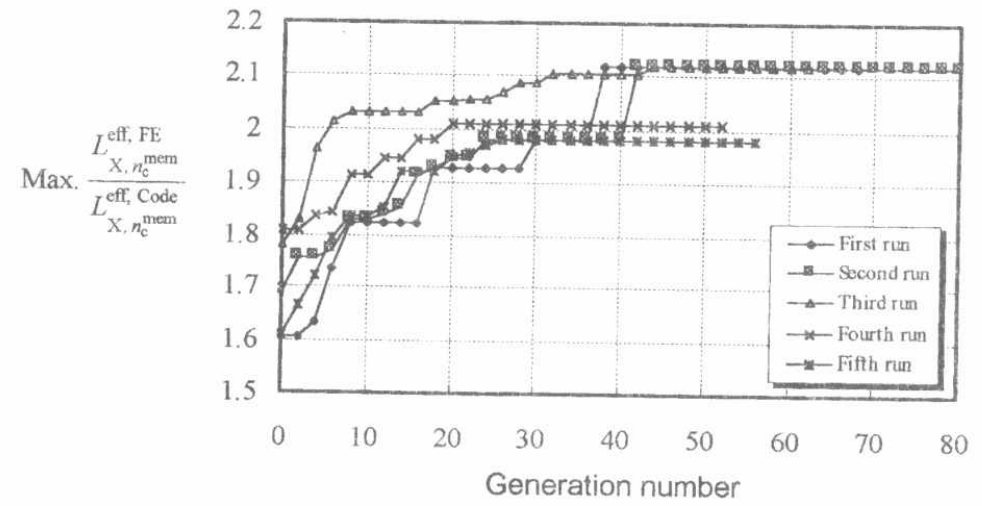

Figure 9. Two-bay two-storey framework ( 6 design variables): maximum $L_{\mathrm{X}, n_{\mathrm{c}}^{\text {mern }}}^{\text {eff, } \mathrm{FE}} / L_{\mathrm{X}, n_{\mathrm{c}}^{\text {mem }}}^{\text {eff, }}$ versus generation number 
Proceedings of the $9^{\text {th }}$ ASAT Conference, 8-10 May $2001 \quad$ Paper ST-20 597

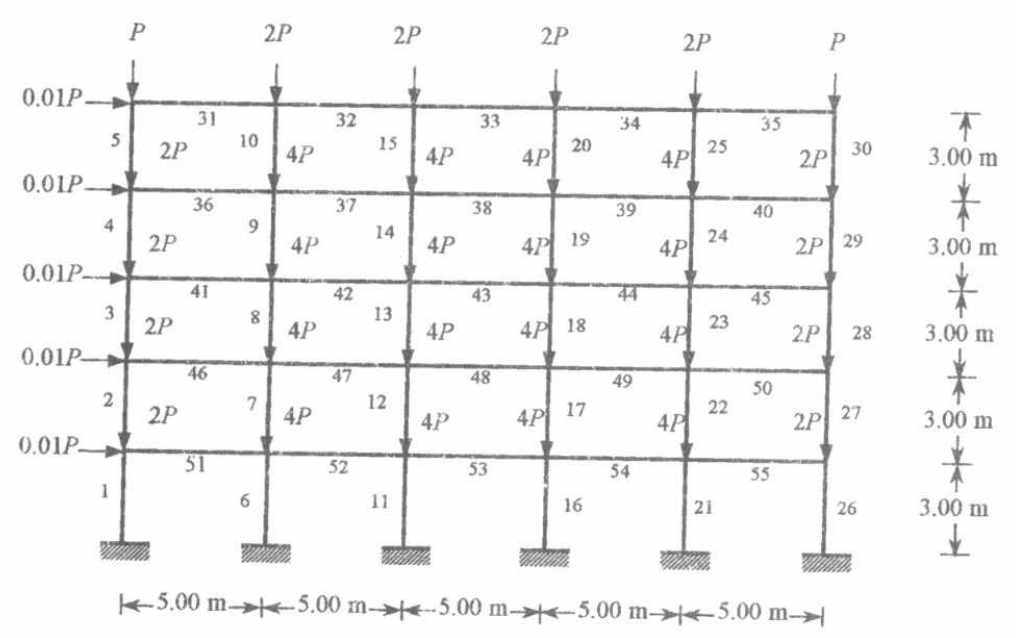

Figure 10. Five-bay five--storey framework: loading pattern for the stability analysis and member numbering

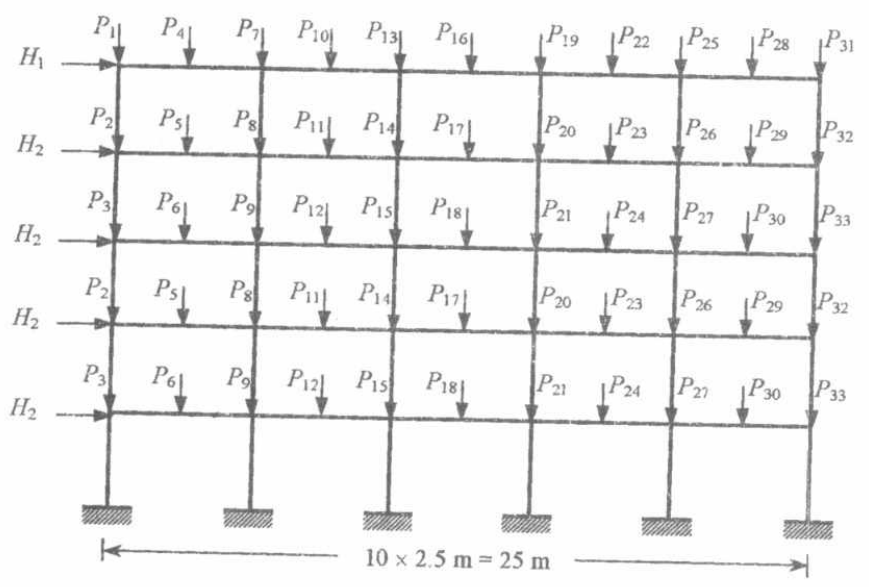

Figure 11. Five-bay five-storey framework: the general loading pattern 


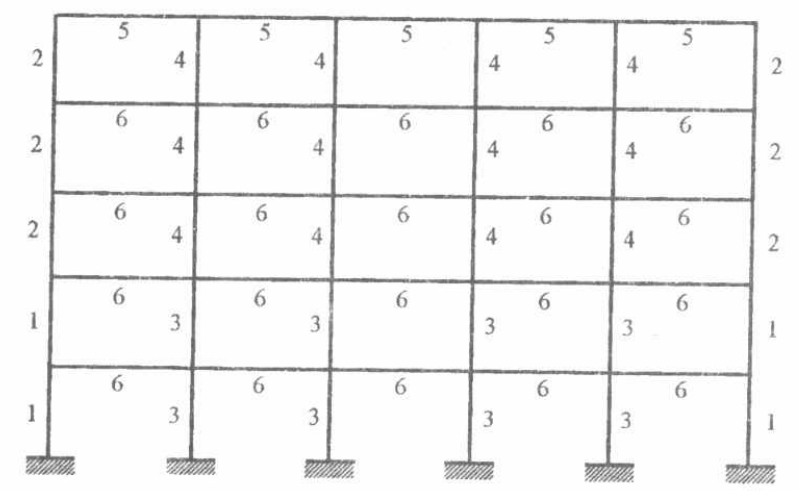

Figure 12. Five--bay five-storey framework: the arrangernent of 6 design variables

\begin{tabular}{|c|c|c|c|c|c|}
\hline 3 & $\begin{array}{ll}7 & 6\end{array}$ & $\begin{array}{ll}7 & 6\end{array}$ & 7 & 67 & 6 \\
\hline 2 & $\begin{array}{ll}8 & \end{array}$ & $\begin{array}{ll}8 & \end{array}$ & 8 & 58 & 5 \\
\hline 2 & $\begin{array}{l}85 \\
\end{array}$ & $\begin{array}{ll}8 & 5\end{array}$ & 8 & 5 & 5 \\
\hline 1 & $\begin{array}{ll}8 & \\
& 4\end{array}$ & $\begin{array}{ll}8 & \\
& 4\end{array}$ & 8 & 4 & 4 \\
\hline 1 & $\begin{array}{ll}8 & \\
& 4\end{array}$ & $\begin{array}{ll}8 & \\
& 4\end{array}$ & 8 & 48 & 48 \\
\hline
\end{tabular}

Figure 13. Five-bay five-storey framework: the arrangement of 8 design variables 


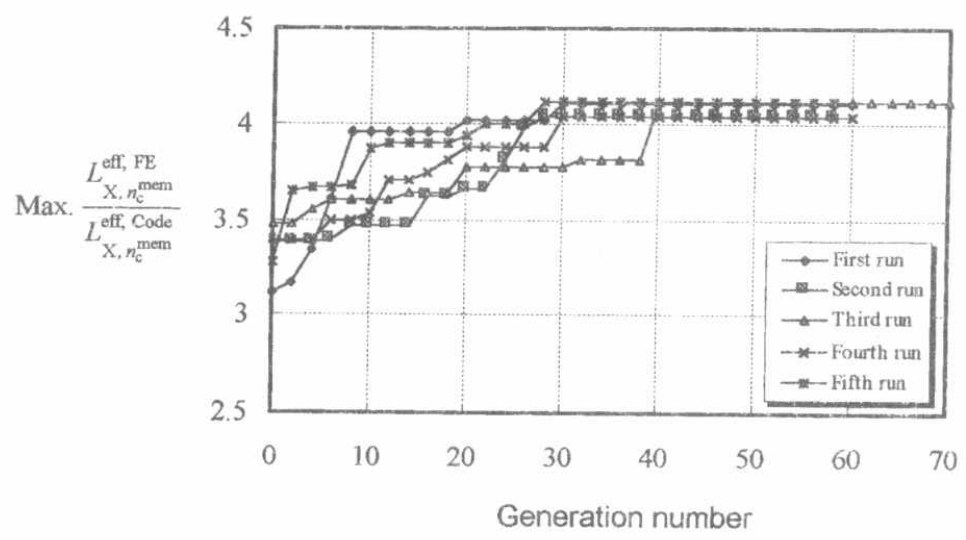

Figure 14. Five-bay five-storey framework ( 6 design variables): maximum $L_{\mathrm{X}, n_{\mathrm{c}}^{\text {mem }}}^{\mathrm{eff}} / L_{\mathrm{X}, n_{\mathrm{c}}^{\text {mem }}}^{\text {eff, Code }}$ versus generation number

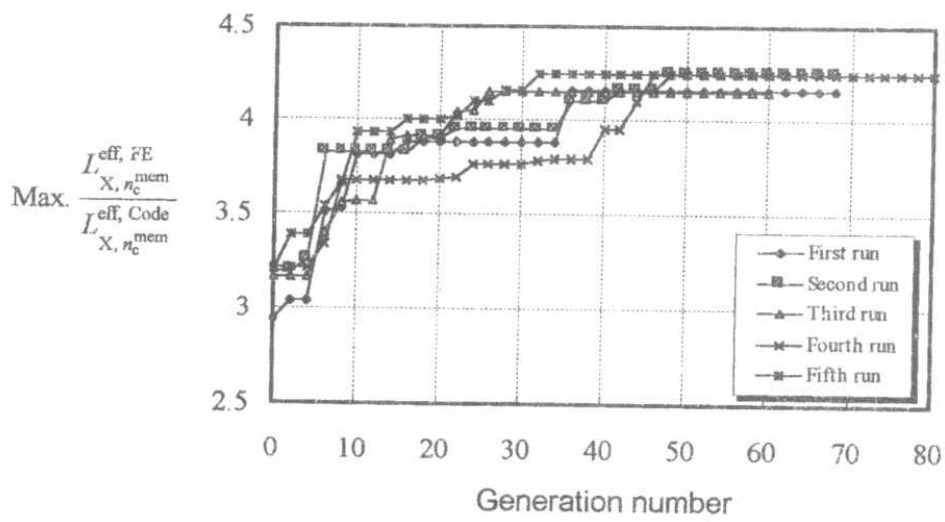

Figure 15. Five--bay five-storey framework ( 8 design variables): maximum $L_{\mathrm{X}, n_{\mathrm{c}}^{\text {mem }}}^{\mathrm{efff}} / L_{\mathrm{X}, n_{\mathrm{c}}^{\text {mem }}}^{\text {effec }}$ versus generation number 